March - 2010

\title{
IRRODL Policy Changes
}

\author{
Terry Anderson \\ Editor, IRRODL
}

The ongoing trend to openness, transparency, and accessibility affects each of us and our institutions, including this journal. This issue announces an important change to IRRODL's licensing requirements and a clarification of IRRODL policies.

We have changed our Creative Commons licensing to provide increased use and exposure of published articles. IRRODL's editorial board has decided to move from the Creative Commons Attribution, Noncommercial, No Derivative Works accessible and simpler Creative Commons Attribution licence.

When we first adopted Creative Commons licensing we felt that others should NOT be able to extend the works of our authors directly (even with attribution) by creating derivative products. For example, without the 'no derivatives' restriction, a third publisher could merge two articles, creating a third, or produce an aggregated compilation of IRRODL articles. We decided that this re-use of our materials really does not hurt us in any substantial way, and it could increase readership, while maintaining attribution. Thus, we felt we would like to try licensing without the 'no derivatives' restriction.

The second change was the removal of the Creative Commons licence restriction on commercial re-use. We have given permission to aggregators (e.g., EBSCO) to add IRRODL to the list of journal databases that they sell to libraries and thus were in some ways violating our own licence. In addition, we are aware that in many developing countries, sometimes small, commercial micro-publishers are the only way to get print materials to students and scholars. After considered debate, the editorial board concluded that removing both the no derivatives and the commercial prohibitions, while retaining the attribution requirement, serves to increase accessibility and openness and is consistent with IRRODL's mission. We will thus request that authors wishing to publish in IRRODL license their work to us under the Creative Commons Attribution licence.

We were also motivated to change our licensing so that we would be eligible for the Scholarly Publishing and Academic Resources Coalition Europe seal. SPARC is a leading organization of European research libraries. This certification is awarded only to open access journals that license 
via the most open of Creative Commons licences (CC-BY) and to those journals (like IRRODL) that share their article metadata. Thus we look forward to being eligible for the SPARC seal, to maximizing the exposure and distribution of IRRODL work, and to continuing to push ourselves and others to expand access to quality academic publications.

\section{Publishing Previously Distributed Content}

The editorial board also discussed the contentious issues that may arise when an author re-uses materials presented at a conference or distributed via a blog, wiki, or other net-based distribution service. We made a useful distinction between publication (distribution after review, editing, and quality control asserted through publication procedures) and distribution (sharing with no quality controls). In pre-Internet days, the only effective way to distribute was through publication, but those days are long past. We thus adopted the following new guidelines:

1. Every article must maintain a high quality of scholarship, not plagiarize the work of others, and make a contribution to the field of open and distance education scholarship.

2. Articles published or under review by other peer review commercial or scholarly publishers are not eligible for publication in IRRODL.

3. Articles distributed as conference proceedings or self-published in blogs or institutional repositories should normally be revised substantially before review and possible publication by IRRODL. (The editor may ask to review in detail the publication/distribution history of any work to make this determination.)

4. Articles that appeared in conference proceedings or were self-published shall acknowledge this distribution history in a footnote.

5. Authors submitting articles that were previously distributed should detail the rationale for review and publication by IRRODL in a note to the editor.

We welcome reader and author responses to either of these two board decisions.

\section{General Issue 11(1)}

This issue gathers seven research articles, two articles from the field, one book review, and three Cider sessions on an eclectic set of themes from four continents. The works focus on many learning sectors and many disciplines but have in common their contribution to the development of our practice and research in open and distance education.

The first research article, Deimann and Bastiaens's “The Role of Volition in Distance Education: An Exploration of its Capacities," focuses on a topic that is critically important but often elusive to both teachers and students, that of volition. In the second article, "Learning in an Online Distance Education Course: Experiences of Three International Students,” Zhang and Kenny provide a case study of the experiences of students enrolled in online courses offered by a foreign institution.The third article, "An Investigation of Distance Education in North American Research Literature using Co-Word Analysis,” by Ritzhaupt, Stewart, Smith, and Barron provides a novel 
way to examine the distance education research literature quantitatively, using co-word analysis of the productions of two major distance education journals. The next article by Barnard-Brak, Paton, and Lan, "Profiles in Self-Regulated Learning in the Online Learning Environment," pushes our understandings of the profiles students exhibit in distance education contexts and helps educators support the development of self-regulation by their students.

The next article focuses on teacher professional development that is flexible and unconstrained by time and distance. Marrero, Fitzsimons Riccio, Woodruff, and Schuster present the results of distributed professional development courses in "Live, Online Short-Courses: A Case Study of Innovative Teacher Professional Development.” The next article, "The Comparative Instructional Effectiveness of Print-Based and Video-Based Instructional Materials for Teaching Practical Skills at a Distance," takes us to Africa. Donkor's article is one of the few IRRODL has published on the effective delivery at a distance of vocational education. Finally, we conclude the research section with a fascinating examination of the effectiveness of mobile learning technologies. Valk, Rashid, and Elder examine six mLearning projects in "Using Mobile Phones to Improve Educational Outcomes: An Analysis of Evidence from Asia.”

This issue also features two articles in our Field Notes section, one from the South Pacific and the other from Europe. In "Reaching REMOTE Learners: Successes and Challenges for Students in an Online Graduate Degree Program in the Pacific Islands," Rao and Giuli overview the unique challenges of delivering graduate programming to students distributed across some of the most sparsely populated regions of the earth. The second article by Cunningham, Fägersten, and Holmsten, "Can you Hear Me, Hanoi? Compensatory Mechanisms Employed in Synchronous Net-Based English Language Learning,” discusses the challenges of incorporating students from other countries into synchronous online foreign language courses.
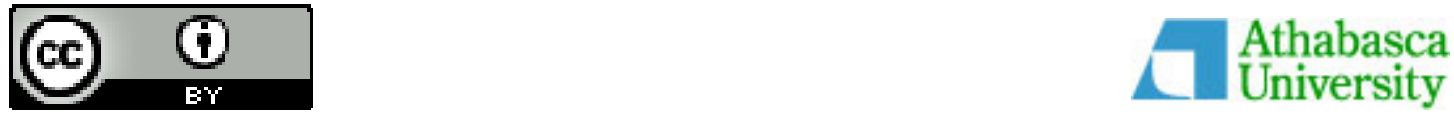